\title{
Selective Modulation of the Pupil Light Reflex by Microstimulation of Prefrontal Cortex
}

\author{
R. Becket Ebitz ${ }^{1}$ and Tirin Moore ${ }^{1,2}$ \\ 'Department of Neurobiology and ${ }^{2}$ Howard Hughes Medical Institute, Stanford University School of Medicine, Stanford, California 94305
}

The prefrontal cortex (PFC) is thought to flexibly regulate sensorimotor responses, perhaps through modulating activity in other circuits. However, the scope of that control remains unknown: it remains unclear whether the PFC can modulate basic reflexes. One canonical example of a central reflex is the pupil light reflex (PLR): the automatic constriction of the pupil in response to luminance increments. Unlike pupil size, which depends on the interaction of multiple physiological and neuromodulatory influences, the PLR reflects the action of a simple brainstem circuit. However, emerging behavioral evidence suggests that the PLR may be modulated by cognitive processes. Although the neural basis of these modulations remains unknown, one possible source is the PFC, particularly the frontal eye field (FEF), an area of the PFC implicated in the control of attention. We show that microstimulation of the rhesus macaque FEF alters the magnitude of the PLR in a spatially specific manner. FEF microstimulation enhanced the PLR to probes presented within the stimulated visual field, but suppressed the PLR to probes at nonoverlapping locations. The spatial specificity of this effect parallels the effect of FEF stimulation on attention and suggests that FEF is capable of modulating visuomotor transformations performed at a lower level than was previously known. These results provide evidence of the selective regulation of a basic brainstem reflex by the PFC.

Key words: frontal eye field; prefrontal cortex; pupil constriction; pupil light reflex; reflex control; subsumption architecture

\section{Significance Statement}

The pupil light reflex (PLR) is our brain's first and most fundamental mechanism for light adaptation. Although it is often described in textbooks as being an immutable reflex, converging evidence suggests that the magnitude of the PLR is modulated by cognitive factors. The neural bases of these modulations are unknown. Here, we report that microstimulation in the prefrontal cortex (PFC) modulates the gain of the PLR, changing how a simple reflex circuit responds to physically identical stimuli. These results suggest that control structures such as the PFC can add complexity and flexibility to even a basic brainstem circuit.

\section{Introduction}

Nervous systems must evolve complex and flexible capacities without sacrificing their basic competencies. One circuit motif that can address this challenge is the development of flexible control systems that regulate existing stimulus-response circuits (Krasne and Wine, 1975; Brooks, 1986; Prescott et al., 1999). This precise mechanism - when a higher-order structure without the

Received July 30, 2016; revised March 14, 2017; accepted March 15, 2017.

Author contributions: R.B.E. and T.M. designed research; R.B.E. performed research; R.B.E. and T.M. analyzed data; R.B.E. and T.M. wrote the paper.

This work was supported by the National Eye Institute-National Institutes of Health (Grant R01-EY014924 and a NEI T32 Postdoctoral Training Grant) and the National Institute of Mental Health-National Institutes of Health (National Research Service Award F32-MH102049 to R.B.E.). We thank Marc Zirnsak and Nick Steinmetz for technical help, Matt Panicello and two anonymous reviewers for helpful comments on the manuscript, and Shellie Hyde and Doug Aldrich for assistance with animal care and husbandry.

The authors declare no competing financial interests.

Correspondence should be addressed to R. Becket Ebitz, Neuroscience Institute, Washington Road, Princeton University, Princeton, NJ 08544. E-mail: rebitz@gmail.com.

DOI:10.1523/JNEUROSCI.2433-16.2017

Copyright $\odot 2017$ the authors $\quad 0270-6474 / 17 / 375008-11 \$ 15.00 / 0$ capacity to produce an action directly modulates information processing in a more basic circuit-has been referred to as a "subsumption architecture" (Brooks, 1986). Subsumption architectures are ubiquitous in modern robotics and circuit motifs that resemble subsumption architectures are common in interactions between the CNS and peripheral reflexes (Krasne and Wine, 1975; Vu et al., 1993; Büschges and Manira, 1998; Delcomyn, 1999; Kimura et al., 2006). However, it is unclear whether these motifs are also present within the CNS. At the highest level of the CNS, the prefrontal cortex (PFC) is thought add flexibility to stimulus-response mappings (Miller and Cohen, 2001). For example, the same region in PFC both transmits motor commands to the brainstem (Schlag-Rey et al., 1992) and modulates visual activity in posterior visual cortex (Moore and Armstrong, 2003; Armstrong et al., 2006; Ekstrom et al., 2008). However, the extent to which the PFC regulates the action of identified stimulus-response circuits remains unknown. Here, we address this question by investigating whether microstimulation of the primate PFC is capable of modulating the action of a basic brainstem reflex. 
The pupil light reflex (PLR) is the first and most fundamental mechanism for light adaptation. It is a transient constriction in pupil size caused by light increments or bright probe stimuli (Loewenfeld, 1993). The PLR is the result of a simple, evolutionarily conserved (Clarke et al., 2003) brainstem circuit in which luminance information from the retina is relayed to the pretectum and then to the Edinger-Westphal nucleus, which in turn commands the pupillary sphincter to contract (Loewenfeld, 1993; Gamlin et al., 1995). Variability in the PLR is only very weakly correlated with pupil size under constant luminance (Ebitz et al., 2014), suggesting that it is largely independent of other, nonselective changes in pupil diameter such as those due to arousal. Nevertheless, PLR magnitude is not solely determined by retinal input. For example, one early study noted that PLR magnitude covaried with successful report of physically identical near-threshold probes (Hakerem and Sutton, 1966). More recent evidence has demonstrated that the PLR can be modulated in a spatially selective manner by selective attention. PLR magnitude is more dependent on the luminance of a probe stimulus when it is attended covertly (Binda et al., 2013; Mathôt et al., 2013; Ebitz et al., 2014) or targeted with a saccade (Ebitz et al., 2014; Mathôt et al., 2015). However, the neural bases of these spatially selective cognitive modulations remain unknown.

One possible source of PLR modulations are gaze control structures such as the frontal eye field (FEF), a structure thought to link cognition such as attention (Moore and Fallah, 2001; Moore and Fallah, 2004; Gregoriou et al., 2012; Squire et al., 2013) to brainstem circuitry, where saccadic eye movements are triggered (Künzle and Akert, 1977; Segraves and Goldberg, 1987; Stanton et al., 1988). The FEF is a prefrontal area with an established role in the same aspects of visual spatial attention (Moore and Fallah, 2001; Gregoriou et al., 2012; Squire et al., 2013) that predict variation in the PLR (Binda et al., 2013; Mathôt et al., 2013, 2015 Ebitz et al., 2014; Binda and Murray, 2015). Moreover, in addition to its organized projections to posterior visual cortex (Stanton et al., 1995) and to brainstem oculomotor centers (Segraves and Goldberg, 1987; Stanton et al., 1988), the FEF projects to the pretectum (Künzle and Akert, 1977; Leichnetz, 1982; Huerta et al., 1986; Stanton et al., 1988), a critical node in the PLR circuit (Gamlin et al., 1995). However, whether input from the FEF is sufficient to modulate this-or any-brainstem reflex is not known.

\section{Materials and Methods}

\section{Surgical procedures and general behavioral techniques}

All experimental procedures were in accordance with the National Institutes of Health's Guide for the Care and Use of Laboratory Animals, the Society for Neuroscience Guidelines and Policies, and the Stanford University Animal Care and Use Committee. Two male rhesus macaques participated in this experiment (Monkey O: 16 sessions, Monkey B: 16 sessions). General surgical procedures have been described previously (Armstrong et al., 2006). Briefly, each animal was surgically implanted with a titanium head post and a recording chamber. FEF recording and stimulation chambers (internal diameter $19 \mathrm{~mm}$ ) were centered at $\sim 20-23 \mathrm{~mm}$ anterior to interaural zero and $17-19 \mathrm{~mm}$ lateral of midline based both on published coordinates (Paxinos et al., 2000; Saleem and Logothetis, 2012) and on previous studies in our laboratory in which the localization of the FEF chamber was guided by magnetic resonance imaging (Armstrong et al., 2009; Zirnsak et al., 2014). Accurate placement of the cylinder was confirmed postmortem in Monkey B. A craniotomy was subsequently performed within the cylinder, allowing access to the FEF on the anterior bank of the arcuate sulcus. All surgery was conducted using aseptic techniques under general anesthesia (isoflurane), and analgesics were provided during postsurgical recovery. A craniotomy was performed on each animal, allowing access to the FEF on the anterior bank of the arcuate sulcus.

The animals were maintained on controlled access to fluids to motivate them to perform the task. Eye position and pupil size were monitored at $1000 \mathrm{~Hz}$ via an infrared eye-tracking system (Eyelink 1000; SR Research) using the manufacturer's standard algorithms. MATLAB (Psychtoolbox-3; Brainard, 1997) was used to display stimuli, trigger stimulation, and record behavior. The tasks were presented on a $47.5-\mathrm{cm}$-wide LCD monitor (Samsung; $120 \mathrm{~Hz}$ refresh rate, $1680 \times 1050$ resolution) located $34 \mathrm{~cm}$ in front of the monkey. For both tasks, the monkeys were trained to maintain fixation (within $\pm 3^{\circ}$ of error) on a central fixation square (subtending $0.5^{\circ}$ ).

\section{Electrical microstimulation and FEF localization}

Electrical microstimulation consisted of cathode-leading, biphasic, square-wave trains with pulses $(0.3 \mathrm{~ms}$ pulse duration, $100 \mathrm{~ms}$ pulse train) delivered at $333 \mathrm{~Hz}$ with a stimulator (S88) and two stimulation isolation units (PSIU-6) (Grass Instruments). Current amplitude was measured via the voltage drop across a $1 \mathrm{k} \Omega$ resistor in series with the return lead of the current source. Before the experimental sessions, FEF sites were localized within the recording cylinder. Low impedance $(\sim 50$ $\mathrm{k} \Omega$ ) stimulating electrodes were inserted in the posterior aspect of the chamber and high-current, long-train duration stimulation was delivered ( $150 \mathrm{uA}, 500 \mathrm{~ms})$. Over the course of several days, stimulating sites were advanced anteriorly to locate sites from which nonsaccadic motor responses were evoked (e.g., shoulder, facial, or arm movements) indicative of premotor cortex (Graziano et al., 2002). Then, stimulating sites were advanced anteriorly until saccades were evoked at depths, current thresholds, and latencies that were consistent with the FEF based on the criteria of numerous earlier studies (Bruce et al., 1985; Schall, 1991; Gold and Shadlen, 2000; Tehovnik et al., 2000; Moore and Fallah, 2001; Buschman and Miller, 2007; Gregoriou et al., 2012; Heitz and Schall, 2012). As in these previous studies, localization of the FEF was established by the ability to evoke short-latency $(<50 \mathrm{~ms})$, fixed-vector, saccadic eye movements with stimulation at currents generally $<50 \mu \mathrm{A}$.

In each experiment, once a candidate FEF site was identified, the threshold current for that site was measured in a standard task ("FEF localizer" task). In this task, the monkey held fixation for a variable duration $(210-6540 \mathrm{~ms}$, mean $=1900 \mathrm{~ms})$ before a microstimulation train was triggered manually by the experimenter. Microstimulation was only delivered if the eye was within $3^{\circ}$ of fixation at the time that the pulse was triggered. Monkeys received a juice reward after stimulation regardless of whether they made a saccade. Multiple stimulation trains were delivered at varying currents $(8-150 \mu \mathrm{A} ; 3-8$ current levels per session) to determine the current threshold required to evoke a saccade, as well as the location of the site's movement field ("stimulated field") (Moore and Fallah, 2004). In addition to the sites tested in the main task, data were collected during an additional 12 sessions with only the FEF localizer task at the same coordinates in the recording cylinder. Of the 32 sessions collected in concert with the main task, the average eccentricity of stimulated fields was $\sim 8^{\circ}$ (range $3-21^{\circ}$ ) and sites were distributed throughout the contralateral hemifield (see Fig. $6 A$ ). In the 32 sessions, sites in Monkey B tended to be below the horizontal meridian and sites in Monkey $\mathrm{O}$ tended to be above it.

Stimulation currents for the main task were set with a two-step process. First, we calculated the threshold current, the current level at which $50 \%$ of stimulation trains elicited saccades in $<50 \mathrm{~ms}$. Next, the stimulating current was initially set slightly below this value (i.e., if the threshold was $40 \mu \mathrm{A}$, then the subthreshold stimulation could initially be set to $30 \mu \mathrm{A})$. We then delivered stimulation at this level to determine whether saccades were elicited. If saccades were elicited, the current was then lowered until no saccades were elicited. Similar to previous studies using subthreshold microstimulation (Moore and Fallah, 2001; Cavanaugh and Wurtz, 2004; Müller et al., 2005; Ekstrom et al., 2008), this resulted in subthreshold test currents that were $<50 \%$ of the current threshold. The average threshold current level was $40 \mu \mathrm{A}( \pm 10.5 \mathrm{SD}$, range $18-62 \mu \mathrm{A})$ and subthreshold stimulation levels used in the main task averaged 16.1 $( \pm 4.6 \mathrm{SD}$, range $8-32 \mu \mathrm{A})$. On average, stimulation currents were set to $42 \%$ of the threshold current $( \pm 12 \% \mathrm{SD}$, range $18-60 \%)$. 


\section{Main task}

After a variable initial fixation period (500-1200 ms), a bright-probe stimulus was flashed peripherally $\left(3-5^{\circ}\right.$ width) on a subset of trials ( $60-$ $70 \%$ ). Additionally, and independently, on $60 \%$ of trials, subthreshold microstimulation was delivered, typically $40 \mathrm{~ms}$ before probe onset or sham probe onset. To probe the temporal specificity of the effects, probe stimuli were also presented at two additional latencies relative to stimulation ( 80 or $160 \mathrm{~ms}$ ) in a subset of sessions (26/32). When present, these were randomly interleaved with the $40 \mathrm{~ms}$ stimulation-to-probe onset asynchrony (SOA). Combined, these 80 and $160 \mathrm{~ms}$ SOAs appeared in less than half of all stimulation trials and, except where otherwise noted, major analyses included only the $40 \mathrm{~ms}$ SOAs. Sessions contained an average of 445 correct trials (range 246-686) with an average of 292 target presentations (minimum 172) evenly distributed across the probe-in and probe-out locations. An average of 266 stimulation trains were delivered per session (minimum 144). At least 30 trials were initiated per condition in each session (combination of probe location, stimulation presence/absence, and SOA). Intertrial intervals were long to allow recovery time for the pupil (Ebitz and Platt, 2015) and ranged between 2 and $2.75 \mathrm{~s}$.

The eccentricity of probe stimuli ranged from $5^{\circ}$ to $20^{\circ}$ and the offset and angle were determined by the direction and amplitude of microstimulation-evoked saccades at that site (details below). Probes could either be congruent with the microstimulation-evoked saccades (probe-in) or $180^{\circ}$ away at the same eccentricity in the opposite hemifield (probe-out). Continued fixation on the central fixation point for $1500-$ $2000 \mathrm{~ms}$ resulted in a juice reward, which ranged from 0.2 to $0.4 \mathrm{ml}$ per trial, fixed within session.

\section{Visual display and illumination}

In the FEF localizer task, the total luminance of the display in the FEF localizer task was $55 \mathrm{~cd} / \mathrm{m}^{2}$ measured at the center of fixation. In the main task, stimuli were presented against a dark gray background ( 7 $\mathrm{cd} / \mathrm{m}^{2}$ ). For approximately half of the sessions, the fixation square was brighter than the $7 \mathrm{~cd} / \mathrm{m}^{2}$ background $\left(24 \mathrm{~cd} / \mathrm{m}^{2} ; 8 / 16\right.$ in Monkey B, $5 / 16$ in Monkey O). In the remaining sessions, it was equiluminant with the background $\left(7 \mathrm{~cd} / \mathrm{m}^{2} ; 8 / 16\right.$ in Monkey B, 11/16 in Monkey O). In bright fixation sessions, the total display luminance with just fixation and background was $8 \mathrm{~cd} / \mathrm{m}^{2}$ measured at the center of fixation. In equiluminant fixation sessions, total display luminance was $7 \mathrm{~cd} / \mathrm{m}^{2}$. Probe stimuli were bright squares (mean luminance $=100 \mathrm{~cd} / \mathrm{m}^{2}$ ) and the luminance of these stimuli was adjusted $\left( \pm 20 \mathrm{~cd} / \mathrm{m}^{2}\right)$ at the start of each session to a level at which PLRs were observed visually at both probe locations.

Pupil size

Pupil size was sampled at $1 \mathrm{kHz}$ on an Eyelink 1000 infrared eye tracker (SR Research). Any occlusion of the pupil during the fixation period resulted in an error and exclusion of that trial from the present analyses. To quantify pupil dilation during the localizer experiment, we defined a significant evoked dilation as pupil size reaching a maximum between 200 and $600 \mathrm{~ms}$ after stimulation (rather than anywhere else in the epoch $100 \mathrm{~ms}$ before stimulation to $1000 \mathrm{~ms}$ after), with the maximum significantly $>1$. Probe-evoked PLRs were quantified using two different methods to ensure that the reported effects were robust to the specific choice of metric. We examined both the amplitude of the PLR (minima of the response (Ebitz et al., 2014) and the magnitude of the PLR (area of the response (Binda et al., 2013). For both analyses, we first normalized each trial's pupil size to the mean pupil size in the $200 \mathrm{~ms}$ preceding probe onset.

Amplitude. We calculated the amplitude of the PLR $(\phi)$ as the minimum of the normalized pupil response in a $500 \mathrm{~ms}$ epoch centered on the across-session trough of the PLR (trough $\approx 500 \mathrm{~ms}$; epoch $=250-750$ $\mathrm{ms}$ after probe onset). Effects were robust to the specific choice of epoch. This metric effectively differentiated real PLRs from pupil responses to sham probes [probe-on vs sham probe receiver operating characteristic; mean area under the curve (AUC) $=0.94 \pm 0.06 \mathrm{SD}$; Wilcoxon signedrank test, different from 0.5: $p<0.0001$, sign $=32$ ]. Units of $\phi$ reflect percentage of baseline pupil size at the peak of the pupil response on each trial.
Magnitude. To calculate the magnitude (area) of the pupil response, we summed residuals of each normalized pupil trace from the mean probe-absent trace for that session. Residuals were summed across the same $500 \mathrm{~ms}$ window and were again robust to the specific choice of epoch. Although less discriminative than the minimum of the pupil response, this metric also successfully differentiated real PLRs from pupil responses to sham probes (probe-on vs sham probe receiver operating characteristic; mean AUC $=0.89 \pm 0.08 \mathrm{SD}$; Wilcoxon signed-rank test, different from 0.5: $p<0.0001$, sign $=32$ ).

\section{Data analysis}

Data were analyzed with custom scripts in MATLAB. Paired, acrosssession $t$ tests were used for all analyses except as otherwise noted. For the main task, PLR outliers ( \pm 3 SDs from the mean) were identified and removed separately from the probe-on and no-probe trials. Of 11278 total correct trials, 60 outliers were removed $(<1 \%)$. To control for any potential effects of eye movement on pupil size, we also required stability in the $x$ - and $y$-position of the eye before and during the PLR epoch. Trials were excluded if eye speed was $>0.5^{\circ} \mathrm{s}$ for any period between 100 $\mathrm{ms}$ before and $750 \mathrm{~ms}$ after probe onset. Of 11278 total correct trials, 1807 were excluded due to eye movements (16\%).

To determine whether the modulation of the PLR was observed in both monkeys, we fit a GLM (MATLAB glmfit) of the following form to the probe-on trials separately within each monkey as follows:

$$
\phi=\beta_{0}+\beta_{1}\left(\mu_{\text {stim }}\right)+\beta_{2}(\text { probe })+\beta_{3}(\text { probe }) \times\left(\mu_{\text {stim }}\right)
$$

Where $\phi$ was a vector of minimum pupil sizes, as described above, " $\mu_{\text {stim }}$ " was a binary vector indicating the presence (1) or absence (0) of microstimulation, and "probe" was a binary vector indicating that the probe was either within the stimulated field (1) or outside of it (0). Therefore, $\beta 1$ captured the effect of microstimulation on probe-out trials, $\beta 2$ any offset in PLR magnitude between probe-in and probe-out trials, and $\beta 3$ the effect of microstimulation on probe-in trials. Main effects of each session were also included with one term for each session minus one.

To probe the temporal specificity of the modulation of the PLR, we examined the effects of microstimulation on PLR amplitude in the subset of sessions that included different SOAs. To determine whether there was a significant decrease in the efficacy of stimulation with greater SOAs, we fit a model that assumed the stimulation effects varied with the SOAs ("temporal-specificity model"). This model added the following terms to the previous ("no-specificity") model:

$$
\begin{aligned}
\ldots+\beta_{4}\left(\mu_{\text {stim }}\right) \times(S O A)+\beta_{5}(\text { probe }) & \times(S O A) \\
& +\beta_{6}\left(\mu_{\text {stim }}\right) \times(\text { probe }) \times(S O A)
\end{aligned}
$$

Where SOA was a vector of centered SOAs. Therefore, $\beta 4$ captured the interaction between microstimulation and SOA on probe-out trials, $\beta 5$ captured any offset in PLRs due to SOAs, and $\beta 6$ captured the conditional effects of microstimulation on probe-in trials given the SOA.

\section{Model comparison techniques}

For model comparison, we used the standard specification of the Akaike Information Criterion (AIC) and Bayesian Information Criterion (BIC) as follows:

$$
\begin{gathered}
\mathrm{AIC}=2 \times k-2 \times \log (L) \\
\mathrm{BIC}=k \times \log (n)-2 \times \log (L)
\end{gathered}
$$

Where $k$ is the number of fitted parameters in the no-temporalspecificity model and temporal-specificity model, respectively; $n$ is the number of observations; and $\log (\mathrm{L})$ is the fitted $\log$ likelihood. The relative AIC weights of each fitted model $i$ (Burnham and Anderson, 2002) were then calculated as follows:

$$
\text { weight }_{\mathrm{i}}=e^{(\mathrm{AICmin}-\mathrm{AICi}) / 2}
$$

Where AICmin is the smallest AIC value among the fitted models and $\mathrm{AICi}$ is the AIC value of the current model. Weights were normalized to 
A
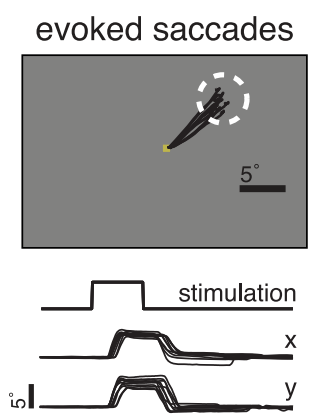

$-100 \quad 0 \quad 100200300400$

time from stimulation (ms)
B

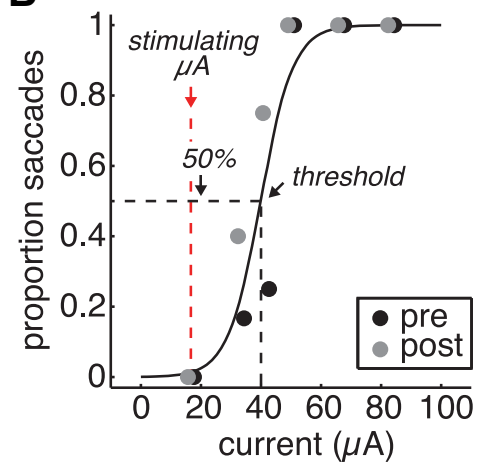

C

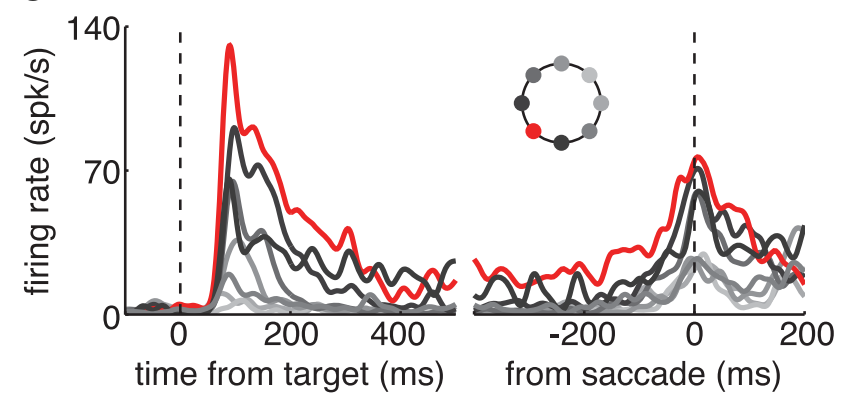

$\mathbf{E}$

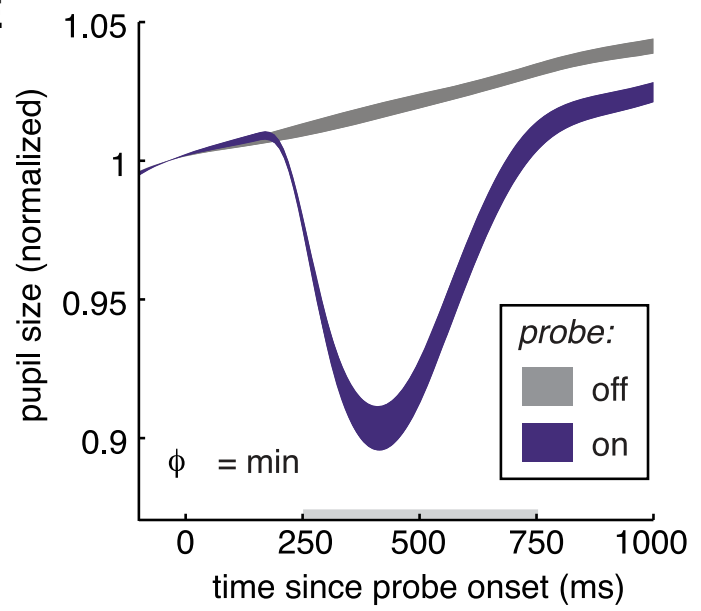

Figure 1. Task design. A, Location to which saccades were evoked ("stimulated field"). B. (urrent thresholds for evoking saccades before and after an example experimental session. The current level for the main task (red arrow) was set below the threshold current. Thresholds and stimulating currents for all sessions are reported in the Materials and Methods. C, Example neuron recorded during a memory-guided saccade task at one of the stimulated sites in Monkey 0 . In the task in which this neuron was recorded, targets were presented for an average of $300 \mathrm{~ms}( \pm 50 \mathrm{~ms}$ ) and then offset for an average of $350 \mathrm{~ms}( \pm 50 \mathrm{~ms})$ before the go cue. The average reaction time after the go cue was $120 \mathrm{~ms} . D, P L R$ task required monkeys to maintain fixation despite flashed probes and FEF microstimulation. Probes could appear in the stimulated field (probe-in) at a location $180^{\circ}$ away (probe-out) or not appear at all (no probe, data not shown). A $100 \mathrm{~ms}$ microstimulation train began $40 \mathrm{~ms}$ before a $67 \mathrm{~ms}$ probe flash. $E$, Pupil response to the presence (purple) or absence (dark gray) of a flashed probe (trace width \pm SE across sessions). PLR was calculated by two metrics: the minimum of the pupil response $(\phi)$ and the sum of residuals between probe responses and the mean probe-absent response in the $500 \mathrm{~ms}$ window shaded in gray.

sum to 1 by dividing each model's weight by the sum of all model weights. BIC values were substituted for AIC values to calculate BIC weights.

\section{Results}

At low currents $(<50 \mu \mathrm{A})$, FEF microstimulation evokes saccades with fixed, retinotopic vectors (Robinson and Fuchs, 1969; Bruce et al., 1985; Tehovnik et al., 2000). Stimulation below the saccade-evoking current threshold ("subthreshold stimulation") causes attention-like changes in perception (Moore and Fallah, 2001; Moore and Fallah, 2004) and extrastriate activity (Moore and Armstrong, 2003; Armstrong et al., 2006) at the retinotopic location that would be targeted by evoked saccades ("stimulated location"). To determine whether FEF microstimulation modulates the PLR in a selective manner, we therefore combined subthreshold FEF microstimulation with PLR-evoking probes in the stimulated location and $180^{\circ}$ away

At each site, we first characterized the stimulated location and current threshold via a standard FEF localizer task (see Materials and Methods; example session in Fig. $1 A, B$ ). Next, in the PLR task ("main task"; Fig. 1D), the two monkeys (16 sessions each) maintained fixation to receive liquid reward. On $60-70 \%$ of trials, a probe stimulus was briefly flashed to elicit a PLR (Fig. 1E). The probes could be within the stimulated field (probe-in) or $180^{\circ}$ away at the same eccentricity (probe-out). On a subset of trials, microstimulation was delivered $40 \mathrm{~ms}$ before probe or sham (no-probe) onset. Mean pupil traces in each condition from an example session are shown in Figure 2. The monkeys performed well (both $>92 \%$ correct). The monkeys were no more likely to break fixation after a probe stimulus than when one was absent (paired $t$ test: $p>0.9, t_{(31)}=0.02$ ), although microstimulation slightly increased the likelihood of broken fixation errors (mean increase $=4 \%$, paired $t$ test, $p<0.008, t_{(31)}=$ 2.82).

\section{Microstimulation effects on the probe-driven PLR}

Across sessions, compared with nonstimulation trials, microstimulation increased the PLR in probe-in trials $\left(p<0.005, t_{(31)}=\right.$ $3.03)$ and decreased it in probe-out trials $\left(p<0.0008, t_{(31)}=\right.$ -3.75 ; Figs. $2 B, C, 3 A$, left). As an additional control for any main effect of stimulation (although none was observed in the main task; Figs. $2 A, 4 A$ ), we also measured PLRs relative to the noprobe baseline. We found the same result: probe-in PLRs were enhanced $\left(p<0.02, t_{(31)}=2.7\right)$, whereas probe-out PLRs were suppressed $\left(p<0.005, t_{(31)}=-3.10\right)$.

We used a generalized linear model (GLM) to test for effects of microstimulation in each monkey individually (see Materials and Methods). Both monkeys had a significant increase in probe-in PLRs with microstimulation (Fig. $3 A$, right; Monkey B: $p<$ 

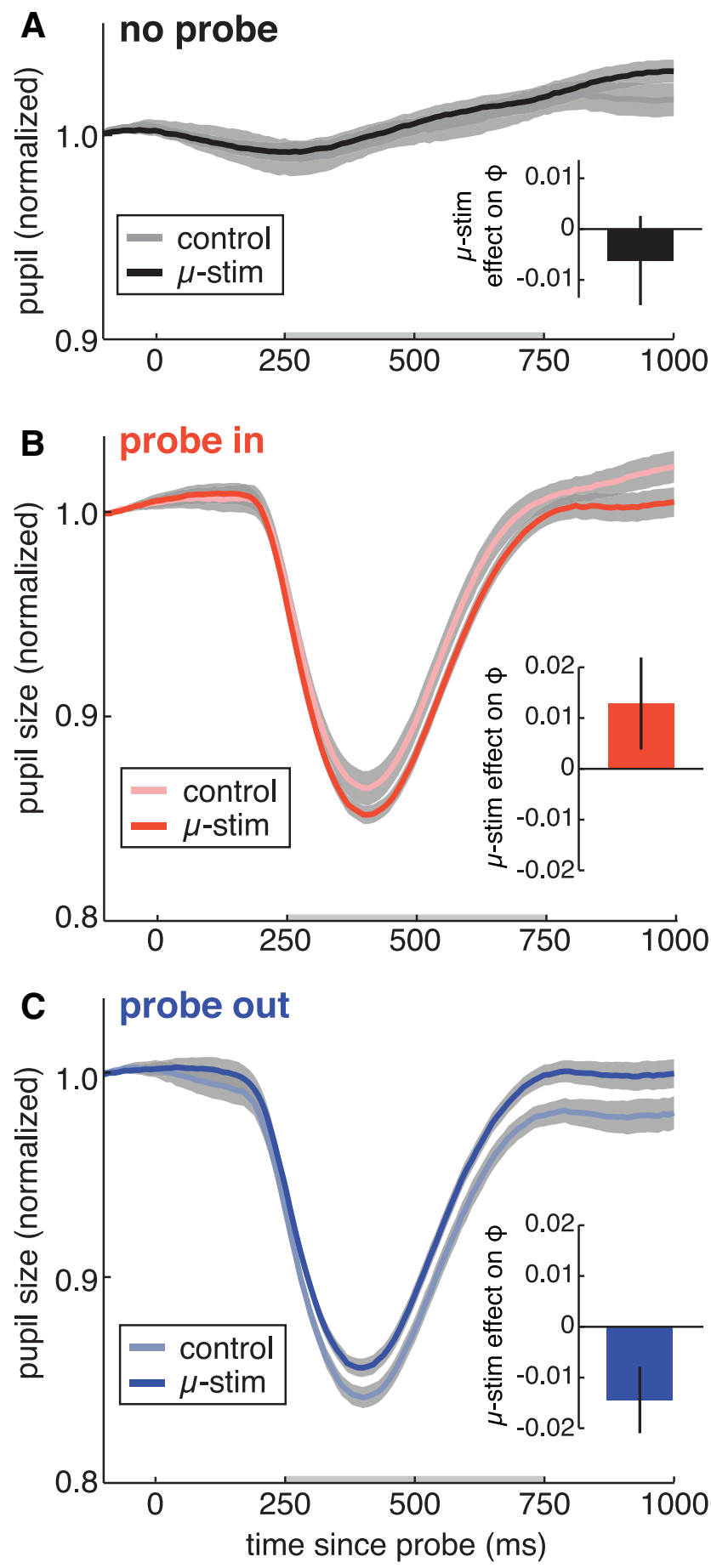

Figure 2. Pupil responses from an example session. $\boldsymbol{A}$, Pupil responses on no-probe trials in one example session (Monkey 0 ). Gray shading is \pm SE. Inset, Stimulation effect: the difference in the minimum pupil size (stimulation - control). Error bars indicate \pm bootstrapped SE of the difference in means. $\boldsymbol{B}, \boldsymbol{C}$, Same as $\boldsymbol{A}$ for probe-in and probe-out trials, respectively.

0.0007, $\beta 3=0.017$; Monkey O: $p<0.007, \beta 3=0.010$; combined: $p<0.0001, \beta 3=0.014$ ) and a significant decrease in probe-out PLRs with microstimulation (Monkey B: $p<0.05$, $\beta 1=-0.007$; Monkey O: $p<0.01, \beta 1=-0.006$; combined: $p<$ $0.0001, \beta 1=-0.008)$. Therefore, subthreshold FEF stimulation selectively and bidirectionally changed the sensitivity of the PLR circuit: it increased sensitivity to probes appearing in the stimulated field and decreased it for probes $180^{\circ}$ away. This type of modulation of the sensitivity of a circuit to a fixed input is often
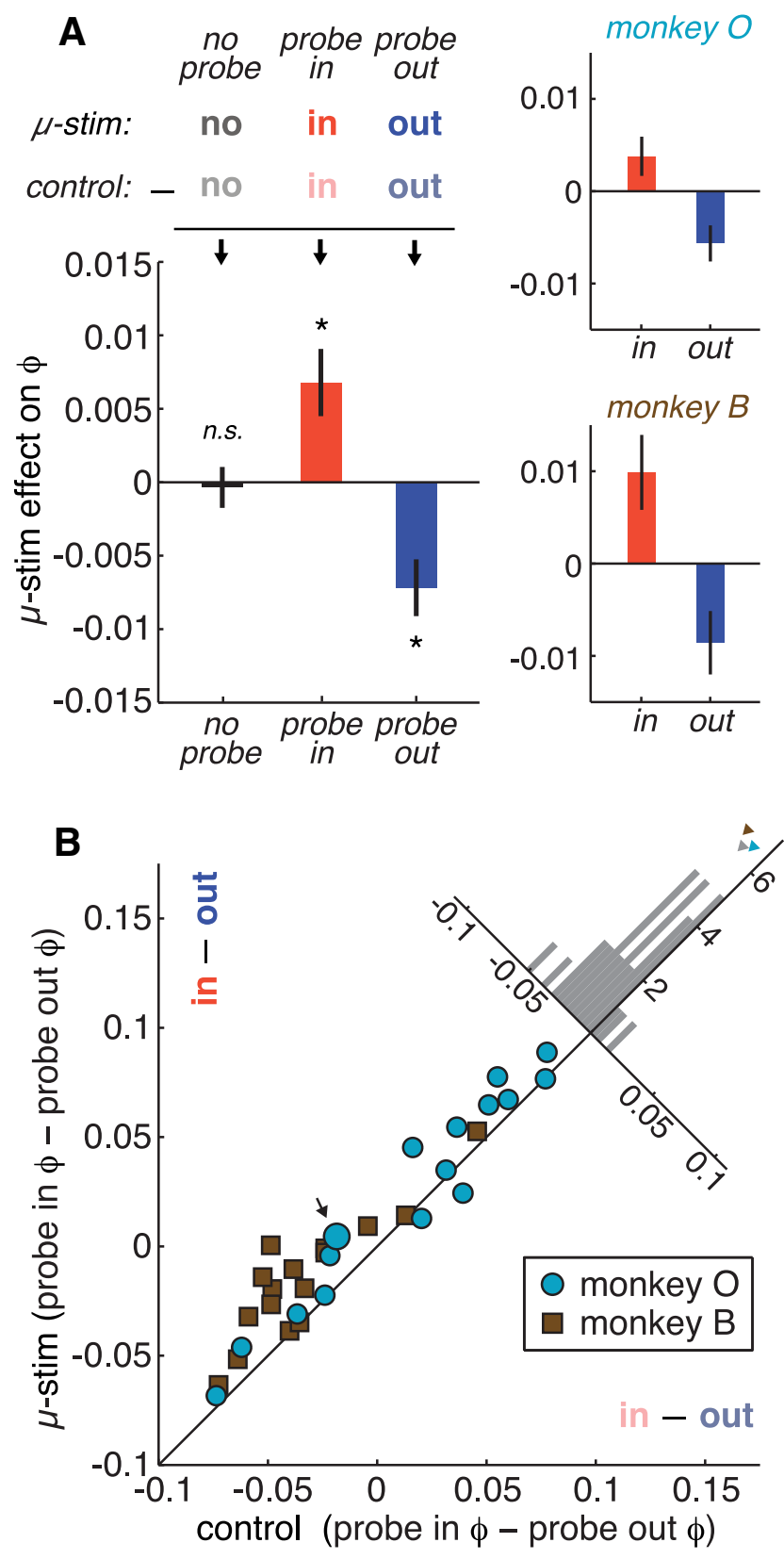

Figure 3. The amplitude of the PLR is modulated by microstimulation. $A$, Microstimulation increased PLR amplitudes on probe-in trials (red) and decreased PLRs on probe-out trials (blue). No change in pupil size was apparent in the absence of probes (black). Right, Same pattern in both Monkey 0 (top) and B (bottom). Error bars are \pm SE across sessions. B, Relationship between probe-in and probe-out PLRs before and after microstimulation. Modulation of the gain of the PLR with stimulation would change the relationship between PLRs on probe-in and probe-out trials, leading to deviations from unity. Black arrow indicates the example session illustrated in Figure 2. Diagonal inset, Distribution of sessions relative to unity. The data are distributed above the unity line for both Monkey 0 (blue circles) and Monkey $B$ (brown squares). Triangles are the means for Monkey 0 (blue), Monkey B (brown), and both combined (gray). ${ }^{*} p<0.05$

called a "gain modulation" (Salinas and Thier, 2000). Therefore, we use the term gain modulation to refer to a change in the difference between probe-in and probe-out PLRs with stimulation. FEF stimulation selectively modulated the gain of the PLR across sessions (data distributed above unity across monkeys, $p<$ $0.0001, t_{(31)}=5.91$; Fig. $\left.3 B\right)$, as well as in each monkey individually (Monkey B: $p<0.0001, t_{(15)}=5.36$; Monkey O: $p<0.006$, $\left.t_{(15)}=3.24\right)$. 

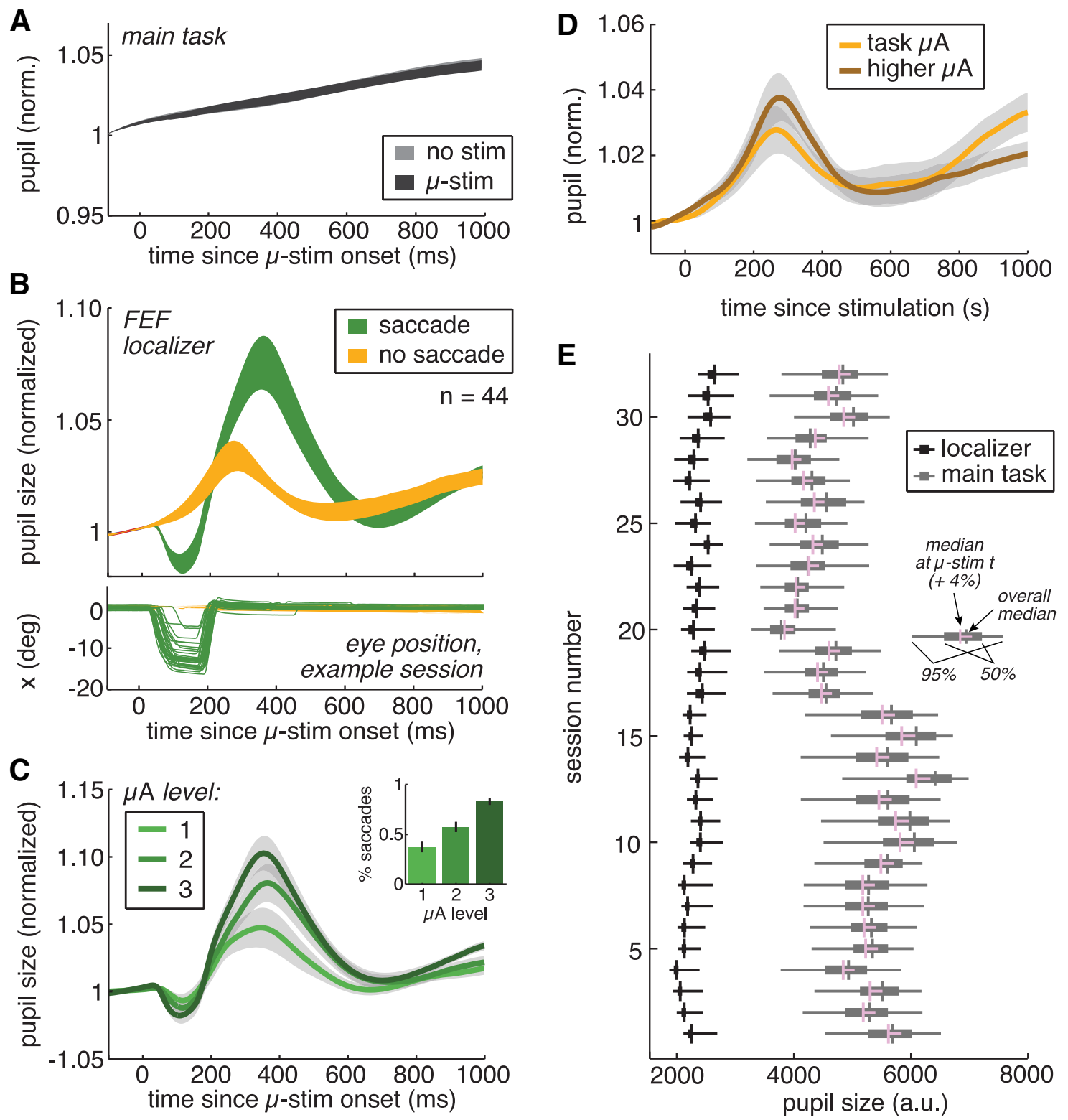

Figure 4. Pupil dilations evoked with microstimulation in the absence of visual probes during the localizer task. $A$, Mean pupil response to microstimulation (and no-stimulation control) when no probes were flashed (trace width \pm SE across sessions, traces are overlaid). $\boldsymbol{B}$, Top, Same as $\boldsymbol{A}$, but in an FEF localizer task (including an additional 12 sessions of the localizer task). Bottom, Eye position from an example session recorded in the FEF localizer task (78 trials). Green traces were identified as evoked saccades, yellow as no-saccade trials. C, Evoked dilations during saccade trials separated into current level bins. Inset, Mean fraction of trials with an evoked saccade for each current level bin ( \pm SE across sessions). $\boldsymbol{D}$, Same as in $\boldsymbol{E}$ for no-saccade trials. Current levels consistent with those delivered in the main task are in dark yellow and higher, but still subsaccadic, currents are in light yellow. $\boldsymbol{E}$, Pupil size at the time of stimulation relative to the measured range of the pupil. Whisker plots show the distribution of measured pupil sizes in the main task (gray bars) and the FEF localizer (black bars). Thick bars are the $50 \%$ interquartile range and thin bars the $95 \%$ confidence interval. The mean pupil size before stimulation (averaged over -200 to $0 \mathrm{~ms}$ ) is overlaid on top of the main task bars (vertical pink bar) and a hypothetical increase in pupil size commensurate with that shown in $\boldsymbol{D}(\sim 4 \%)$ is shown (horizontal pink bar). The top 16 sessions were from Monkey B (17-32), bottom from Monkey 0 (1-16).

Main effects of FEF stimulation on pupil size

Although FEF microstimulation (Lehmann and Corneil, 2016) and stimulation in other oculomotor structures (Wang et al., 2012) has been reported to elicit pupil dilation, we observed no main effect of microstimulation on pupil size in the example session (Fig. $2 A$ ) or across sessions (Fig. $4 A ; p>0.8, t_{(31)}=$ -0.23 ) during the main task. The discrepancy between this result and previous findings required scrutiny. Therefore, we attempted to replicate aspects of the short-latency dilations of the pupil after FEF stimulation as described in Lehmann and Corneil (2016). Specifically, in addition to the dilations themselves, we sought to replicate that such dilations are modulated by stimulation current. Regarding the former, we found that, across 44 sessions of the FEF localizer task (see Materials and Methods), FEF stimulation evoked short-latency pupil dilations that were larger when saccades were evoked than when they were not (Fig. $4 B$ ). We observed significant dilations of the pupil with microstimulation in $15 / 44$ sessions ( $34 \%$ of all sessions in the two monkeys). A similar proportion of significant sessions were observed within the 32 sites in which the main task was run: $31 \%$ of sessions ( 10 sessions). The mean latency of maximal dilation during subsaccadic stimulation was $328 \mathrm{~ms}$ across sessions.

As in Lehmann and Corneil (2016), the magnitude of dilation was increased with increasing stimulation current. Within saccade-evoked trials, currents were divided into three levels with approximately equal trial counts (Fig. 4C). These current levels 
significantly predicted the maximum pupil size $(200-600 \mathrm{~ms}$ poststimulation, $p<0.007, \beta=0.026$ ). Current level also significantly predicted pupil size during the same epoch on no-saccade trials (current levels binarized: above the no-saccade-threshold used in the main task and at this threshold, 9 sessions missing cells, $p=0.02, t_{(35)}=-2.36$ ). Therefore, although microstimulation did not cause dilations in the main task, evoked dilations were possible from the same sites in the FEF localizer task.

\section{Effect of display luminance}

It was possible that the lack of stimulation-evoked dilation in the main task might be due to physiological saturation of the pupil because of the darker display in the main task. We tested this possibility by determining whether the pupil was capable of becoming more dilated than it was at the time of stimulation in the main task (Fig. 4E). We compared median pupil size in the prestimulation period (averaged over the -200 to $0 \mathrm{~ms}$ preceding stimulation) with the distribution of measurements of pupil size collected during other epochs when the eye was within $5^{\circ}$ of fixation in the main task. Prestimulation pupil size was smaller than the median observed pupil size in a large majority of sessions (29/32, paired $t$ test: $\left.p<0.0001, t_{(31)}=-7.78\right)$. Moreover, an evoked dilation commensurate with that observed in the FEF localizer $(\sim 4 \%)$ would have fallen well within the distribution observed pupil sizes in every single session (significantly smaller than the $75 \%$ quartile of observed pupil sizes in 32/32 sessions, $\left.p<0.0001, t_{(31)}=-12.51\right)$. Because larger pupil sizes were physiologically plausible, the lack of stimulation-evoked dilation in the main task was unlikely to be caused by a simple saturation of pupil size.

To confirm that the selective modulation of PLR magnitude was not a simple consequence of low luminance, we manipulated the brightness of the fixation in some sessions. In "equal fixation" sessions, the central fixation was a color-contrasting square the same brightness as the background. In "bright fixation" sessions, the central fixation was brighter than the background. Manipulating fixation luminance modulated pupil size. Pupil size just before stimulation ( -200 to $0 \mathrm{~ms}$ ) was significantly smaller in the bright fixation sessions than in the equal fixation sessions (twoway monkey $X$ fixation luminance ANOVA: main effect of luminance: $p<0.0003, F_{(1,29)}=18.4$; main effect of monkey $=p<$ $\left.0.0001, F_{(1,29)}=184.4\right)$. However, in both equal fixation and bright fixation sessions, microstimulation had no significant direct effect on pupil size (bright fixation: mean change in pupil size $=-0.001, p>0.7$; equal fixation: mean $=0.002, p>0.5$ ). Moreover, in both conditions, FEF microstimulation increased the difference between probe-in and probe-out PLRs (Fig. 5; bright fixation: sig. increase in probe-in minus probe-out, $p<$ $0.005, t_{(12)}=3.5$; equal fixation: $\left.p<0.02, t_{(18)}=2.6\right)$. Effect sizes were comparable across the two conditions (bright fixation $=$ 0.013 ; equal fixation $=0.010$ ) and the distribution of effect sizes were not significantly different between fixation conditions (Kolmogorov-Smirnov test, $p>0.8$, statistic $=0.21$ ).

\section{Localization of stimulation-evoked PLR modulations}

Microstimulation increased the gain of the PLR at sites with stimulated fields distributed across the contralateral visual field (Fig. $6 A$ ). To determine whether there was any systematic effect of stimulated field location on the effect of microstimulation on the gain of the PLR, we first $z$-scored the effect magnitude within the monkey (the increase in the difference in probe in and probe out PLRs with stimulation). $z$-scoring effect magnitude allowed us to combine observations across monkeys with different absolute
A

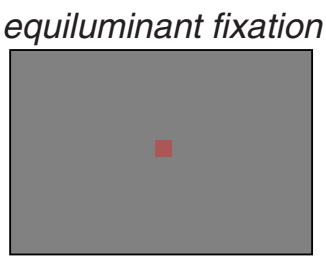

B
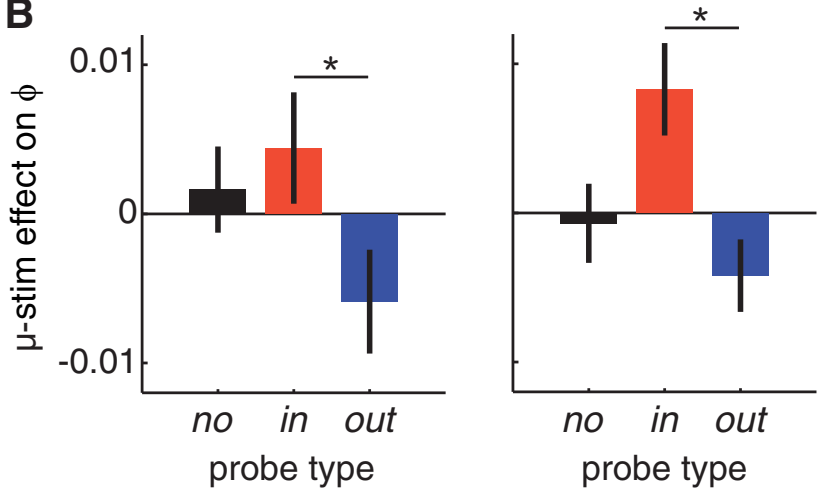

Figure 5. Effect of FEF stimulation on the PLR in different luminance conditions. $\boldsymbol{A}$, Fixation could be either equiluminant with the background (red square) or brighter than the background (yellow square). Error bars are \pm SE across sessions. $\boldsymbol{B}$, Effect of FEF stimulation on PLR amplitude in equal fixation (left) and bright fixation (right) sessions.

effect sizes (Fig. 3A, left). We then examined the correlation between $z$-scored effect magnitude and the eccentricity and angle of stimulated fields. We found no significant correlation between the magnitude of PLR gain modulation and stimulated field eccentricity (Fig. $6 B ; p>0.8$, Pearsons' $r=-0.02$,) or angle (Fig. $6 B ; p>0.3$, Pearsons' $r=0.17$ ). Therefore, microstimulation modulated the gain of the PLR at sites representing heterogeneous loci in the contralateral visual field.

To determine whether the modulatory effect of FEF stimulation on the PLR differed across FEF sites, we also investigated whether there was a correlation between the depth of the stimulation site and the $z$-scored effect size described above. There was no significant correlation between the depth of the stimulated site from the surface of the brain (mean $=5700 \mu \mathrm{M}$, range $750-8800)$ and the magnitude of the modulation of the PLR ( $p=0.33$, Pearson's $r=0.18$ ). However, the depth at which saccades were evoked varied across stimulation sites, so the depth of the site from the surface of the brain provided limited insight into the depth of site relative to the dorsal extent of the FEF in each electrode tract. However, a small subset of sessions $(8 / 32)$ were within the same electrode tract as a first session. These "second" sessions were at least $500 \mu \mathrm{M}$ ventral to the first stimulation site, which was commonly the first location where saccades were evoked at $<50 \mathrm{~ms}$ and $<50 \mu \mathrm{A}$ in that tract. Therefore, these second sessions were systematically more ventral in the arcuate than the first sessions. Although the effect of FEF stimulation on the PLR was only at trend in this small number of sites $(8 / 32, p<$ $0.09 ; t_{(7)}=2.00$; compared with first session sites: $24 / 32, p<$ $\left.0.002 ; t_{(23)}=3.56\right)$, there was no significant difference in the distribution of the effect in these sites compared with the more dorsal sites (Kolmogorov-Smirnov test, $p>0.4$, statistic $=0.33$, mean effect size in second sites $=0.013 \pm 0.003 \mathrm{SE}$, first sites $=$ $0.011 \pm 0.007 \mathrm{SE})$. Therefore, we observed no apparent systematic differences between the depth of the stimulation site and the efficacy of stimulation at modulating the PLR. 
A

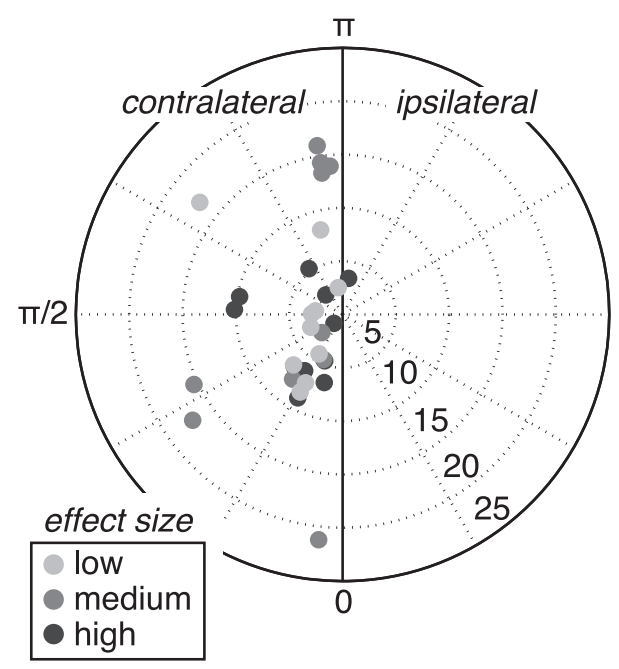

B

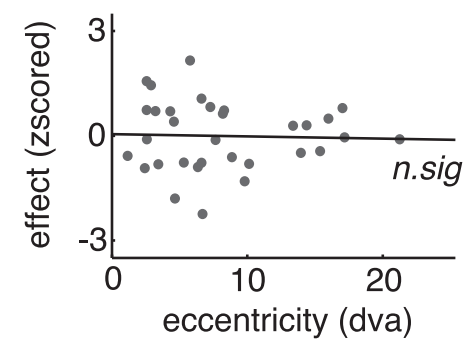

C

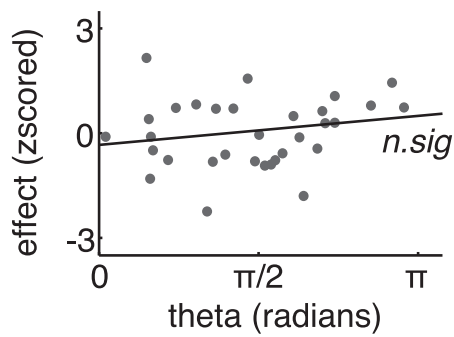

Figure 6. Effect ofFEF microstimulation on the PLR by the location of the stimulated field. $A$, Distribution of the stimulated fields from all 32 sites. The shading of the dot indicates the $z$-scored magnitude of the gain modulation effect (Fig. $3 B$, inset), with the smallest effect sizes in light gray and largest in black. $B, C$, Size of the gain modulation plotted as a function of the eccentricity of the stimulated field $(\boldsymbol{B})$ and the angle ( $\boldsymbol{C}$.

\section{Specificity of stimulation-evoked PLR modulations}

To determine whether the modulation of PLR magnitude was temporally specific, in some sessions $(n=26)$, we included trials with longer SOAs ( 80 and $160 \mathrm{~ms}$ ). We fit a GLM to estimate the effect of SOA on PLR-gain modulations (see Materials and Methods). We found that the effects of FEF microstimulation on the PLR decreased rapidly with increasing SOAs, both for the probeout condition $(\beta 4=0.10, p<0.002)$ and the probe-in condition $(\beta 6=-0.16, p<0.004)$. Post hoc, paired $t$ tests confirmed that microstimulation did not have a significant effect on PLRs at either of the longer ( 80 and $160 \mathrm{~ms}$ ) SOAs (all $p>0.13$ ).

In both the temporal-specificity and no-specificity model (fit only to the sessions with longer SOAs; see Materials and Methods), the sign of the main effects matched those reported in the larger dataset and were significant (no-specificity: $\beta 1=-0.006$, $p<0.0006 ; \beta 3=0.008, p<0.003$; temporal-specificity: $\beta 1=$ $-0.01, p<0.0001 ; \beta 3=0.02, p<0.0001$ ). The offset term was also significant in the temporal-specificity model $(\beta 5=0.16, p<$ 0.0001 ). Finally, we used standard model comparison techniques (Burnham and Anderson, 2002) to determine which of these two models better explained the data. The AIC and BIC are commonly used metrics for model selection. Each is based on the likelihood of the data under a fitted model and has a term that adjusts for the number of free parameters (see Materials and Methods). Both penalize models for the number of free parameters, although BIC imposes a larger penalty than AIC. The model with the lowest AIC and BIC values is the model that best explains the data (minimizes information loss) of the models tested. The no-specificity model had an AIC of 14740 and a BIC of 14968. The temporal-specificity model had lower AIC and BIC values: an AIC of 14704 and a BIC of 14952. Therefore, the temporalspecificity model was a better fit to our data than the nospecificity model. To determine the relative likelihood that each model was the best, we computed AIC weights (see Materials and Methods). This metric quantifies the relative likelihood of each model tested to minimize information loss. The relative AIC weight of the no-specificity model (compared with the temporal- specificity model) was $<2 \times 10^{-8}$ (BIC weight $\left.=4 \times 10^{-4}\right)$, indicating that the temporal-specificity model was a substantially better fit to the data by both metrics. These results thus indicate that the modulation of the PLR depended on the temporal overlap between probe stimuli and FEF stimulation.

Finally, to confirm that the modulation of the PLR was not an artifactual consequence of our choice of PLR metric, we repeated the primary analyses using an alternative measure of the PLR that has also been used in the literature (Binda et al., 2013): the area rather than the minimum of the pupil response (see Materials and Methods). By this measure, microstimulation bidirectionally modulated the PLR in both monkeys together (Fig. $7 A$; data distributed above unity: $p<0.0001, t_{(31)}=$ 5.00 ), as well as individually (Monkey $\mathrm{O}$ : $p<0.03, t_{(15)}=2.40$; Monkey B: $p<$ $\left.0.0002, t_{(15)}=4.91\right)$. This was due to microstimulation enhancing PLRs on probe-in trials (Fig. $7 B ; p<0.008, t_{(31)}=$ 2.86) and suppressing PLRs on probe-out trials (blue; $\left.p<0.01, t_{(29)}=-2.79\right)$. No significant change in pupil size was observed during no-probe trials $\left(p>0.5, t_{(31)}=\right.$ $-0.62)$.

\section{Discussion}

In summary, the present results show that microstimulation of the FEF selectively modulates the PLR. The effect of FEF stimulation on the response of a brainstem-mediated reflex to a fixed input differed depending on the overlap between the stimulation site and the probe stimulus. By definition, the modulation of the response of circuit to a fixed input is a gain modulation (Salinas and Thier, 2000). Here, microstimulation enhanced the constriction evoked by probes presented within the stimulated field and suppressed the constriction evoked by probes $180^{\circ}$ away: it selectively and bidirectionally modulated the reflex pupil constriction caused by a probe (although we would caution that a limited range of display and probe luminances was used here). Nevertheless, the present result suggests that FEF microstimulation can alter the gain of visuomotor transformations at a lower level than was previously known: it can modulate the relationship between a bright stimulus and the reflexive constriction of the pupillary sphincter. This result suggests a competitive, mutually inhibitory architecture, either within the FEF or within downstream structures, such as the pretectum. Within the FEF, microstimulation simultaneously enhances the activity of FEF neurons with similar spatial tuning and suppresses the activity in neurons with different tuning (Schlag et al., 1998). However, the presence of a competitive architecture in the FEF does not rule out competitive interactions localized elsewhere.

\section{Stimulation-evoked dilation}

FEF stimulation did not alter pupil size in the absence of a probe in the main task. However, in other circumstances, FEF stimulation can cause transient pupil dilation, as reported previously (Lehmann and Corneil, 2016) and replicated in the localizer experiment here (Fig. $4 B-D$ ). Activity in many brain regions is correlated with or predicts changes in pupil size under constant 
luminance (Ebitz and Platt, 2015; Joshi et al., 2015; McGinley et al., 2015). Although future electrophysiological recordings are needed to determine whether FEF activity is correlated with pupil size, FEF is among a number of regions in which stimulation causes transient pupil dilation, including the locus ceruleus (Joshi et al., 2015), the superior and inferior colliculus (Wang et al., 2012; Joshi et al., 2015; Wang and Munoz, 2015), and multiple regions in the PFC (Hodes and Magoun, 1942; Ward and Reed, 1946; Joshi et al., 2015; Lehmann and Corneil, 2016). Future work is required to elucidate what factors determine whether FEF stimulation will cause pupil dilation, although perhaps the salience, behavioral relevance, or uncertainty about the timing or strength of stimulation trains may play a role. These factors profoundly determine whether sensory stimuli will elicit pupil dilation (Sokolov, 1963; Friedman et al., 1973; Stelmack and Siddle, 1982; Steinhauer and Hakerem, 1992; Anderson and Yantis, 2012; Nassar et al., 2012; Wang et al., 2014; Wang and Munoz, 2015) and also differed across the main task and the FEF localizer and previous results (Lehmann and Corneil, 2016). It is possible that the effect of direct cortical microstimulation on pupil size also varies with these factors.

One difference between the tasks that seems less likely to explain variation in the likelihood of stimulation-evoked dilations is luminance. Illumination in the main task was low (to maximize the PLR) and this could have saturated pupil size, precluding stimulation-evoked dilations. However, pupil sizes were below the median of observed pupil sizes at the time of stimulation and thus not at ceiling. Moreover, both sympathetically and parasympathetically mediated stimulus-evoked dilation can be observed in single trials from completely dark-adapted pupils (Lowenstein and Loewenfeld, 1950), suggesting that ceiling effects may be unlikely under physiologically typical conditions. Last, it is important to note that, if dilations were indeed evoked during the main task, then they would tend to reduce the magnitude of the selective increase in probe-in PLRs.

\section{Potential mechanisms and future directions}

Most important among our observations is the spatial specificity of the effects of FEF microstimulation on the probe-evoked PLR. This specificity would not be the expected result from a general effect of stimulation on arousal (Bradley et al., 2008; Wang et al., 2012; Lehmann and Corneil, 2016), which should be a unidirectional effect on pupil size that is independent of probe location. Furthermore, the spatial specific effects also indicate that changes in the PLR were unlikely to result from stimulation-driven sensory experiences (e.g., phosphenes, muscle propioception) (Elsley et al., 2007; Murphey and Maunsell, 2008) because such experiences would also be expected to have the same effect on pupil size regardless of probe location. Furthermore, the stimulation currents used were generally below the threshold detectable by the monkey (Murphey and Maunsell, 2008) and thus are unlikely to have been perceived as sensory or other experiences.

Instead, the observed effects of FEF stimulation on the PLR resonate with previous demonstrations of spatially specific effects of stimulation on visual perception and attention (Moore and
Fallah, 2001; Moore and Fallah, 2004; Schafer and Moore, 2007). As in those studies, the effects of FEF stimulation that we observed depended critically on the presentation of the probe in the space represented by neurons at the stimulation site. This dependence suggests that stimulation alters visual processing of spatially corresponding stimuli by the visual system and is consistent with the known effects of FEF stimulation on sensory processing in posterior visual cortex (Moore and Armstrong, 2003; Ekstrom et al., 2008). Evidence from previous FEF stimulation studies, combined with electrophysiological studies (Thompson et al., 2005; Schafer and Moore, 2011) and lesion or inactivation studies (Latto and Cowey, 1971; Monosov et al., 2011; Gregoriou et al., 2014), appear to establish a key role of FEF neurons in the control of visual spatial attention, perhaps via their direct input to extrastriate cortex (Stanton et al., 1995; Merrikhi et al., 2017). Given that attention influences the perceived contrast of visual stimuli (Carrasco et al., 2004) and alters visual processing throughout the visual system, as early as the dorsal lateral geniculate nucleus (McAlonan et al., 2008), the present results could reflect stimulation-driven changes in the representation of probe stimuli by visual neurons and the result of those changes on perception.

These results implicate the FEF as one potential source for the selective perceptual and attentional modulations of the PLR (Laeng and Endestad, 2012; Binda et al., 2013; Mathôt et al., 2013; Ebitz et al., 2014; Binda and Murray, 2015). FEF is implicated in some of the same spatially specific variations in attention (Binda et al., 2013; Mathôt et al., 2013; Ebitz et al., 2014; Binda and Murray, 2015) and perception (Laeng and Endestad, 2012) that predict variation in the PLR. Just as FEF stimulation increased PLRs to probes presented in the space represented by neurons at the stimulation site and decreased PLRs to probes presented $180^{\circ}$ away, converging attention increases PLRs to probes in attended locations and suppresses PLRs to probes in other locations (Ebitz et al., 2014). Future work is needed to determine whether the activity of FEF neurons predicts the PLR on a trial-by-trial basis and, at the same time, predicts perceptual performance of attention-demanding tasks either electrophysiologically or via direct manipulation of FEF activity.

Ultimately, the present results suggest that FEF neurons not only control the direction of the eye, but also the adaptation of its aperture to light. The function of FEF-mediated control of the 
PLR may be to adapt the eye for changes in luminance across saccades (Ebitz et al., 2014; Mathôt and Van der Stigchel, 2015; Mathôt et al., 2015). The targets of sequential saccades can vary in luminance by an order of magnitude (Frazor and Geisler, 2006). Because the pupil takes hundreds of milliseconds to contract, beginning adjustments in pupil size before a saccade may be important for light adaptation in natural vision, ensuring time to adapt the pupil before a bright target is foveated (Mathôt and Van der Stigchel, 2015). Some experimental evidence is consistent with a presaccadic modulation of the PLR. For example, when a target for a saccade is near a PLR-evoking probe, the magnitude of the PLR is larger than when a saccadic target is distant (Ebitz et al., 2014). In addition, the magnitude of the PLR is not affected by changes in the luminance of a target that occur after the saccade has begun (Mathôt et al., 2015).

A major question raised by the present results is the extent to which the FEF has direct (vs indirect) effects on the PLR circuitry. There is anatomical evidence for a direct projection from the FEF to the PLR circuit (Künzle and Akert, 1977; Leichnetz, 1982; Huerta et al., 1986; Stanton et al., 1988). It is possible that these projections underlie the present effects. However, one might expect that a direct projection to the pretectum cause PLR-like pupil response (i.e., evoke constriction). However, the effects of FEF stimulation on pupil size in the main task depended on the presence of a PLR-evoking stimulus. Perhaps it is illustrative to recall that the FEF also projects directly to brainstem oculomotor nuclei, yet FEF stimulation does not elicit eye movements in the absence of a mediating collicular pathway (Hanes and Wurtz, 2001). Perhaps the role of the FEF in pupil constriction is to modulate the responses of the basic PLR circuit rather than to stimulate constriction directly, much like a subsumption architechture in robotics (Brooks, 1986). However, these effects may not be mediated by direct projections from the FEF to the PLR circuit. In addition to its descending input from the FEF, the PLR circuit receives projections from multiple cortical regions with activity that is affected by FEF stimulation (Schlag-Rey et al., 1992; Moore and Armstrong, 2003; Armstrong et al., 2006; Ekstrom et al., 2008), including extrastriate cortex (Dineen and Hendrickson, 1983; Leichnetz, 1990), oculomotor regions in parietal cortex (Leichnetz, 2001), and the superior colliculus (Berman, 1977). Therefore, FEF stimulation could modulate the PLR via affecting a distributed network that in turn shapes the PLR via multiple descending projections. Future work is necessary to determine the precise circuitry by which top-down control signals modulate the gain of the PLR.

\section{References}

Anderson BA, Yantis S (2012) Value-driven attentional and oculomotor capture during goal-directed, unconstrained viewing. Atten Percept Psychophys 74:1644-1653. CrossRef Medline

Armstrong KM, Fitzgerald JK, Moore T (2006) Changes in visual receptive fields with microstimulation of frontal cortex. Neuron 50:791-798. CrossRef Medline

Armstrong KM, Chang MH, Moore T (2009) Selection and maintenance of spatial information by frontal eye field neurons. J Neurosci 29:1562115629. CrossRef Medline

Berman N (1977) Connections of the pretectum in the cat. J Comp Neurol 174:227-254. CrossRef Medline

Binda P, Murray SO (2015) Keeping a large-pupilled eye on high-level visual processing. Trends Cogn Sci 19:1-3. CrossRef Medline

Binda P, Pereverzeva M, Murray SO (2013) Attention to bright surfaces enhances the pupillary light reflex. J Neurosci 33:2199-2204. CrossRef Medline

Bradley MM, Miccoli L, Escrig MA, Lang PJ (2008) The pupil as a measure of emotional arousal and autonomic activation. Psychophysiology 45: 602-607. CrossRef Medline
Brainard DH (1997) The psychophysics toolbox. Spat Vis 10:433-436. CrossRef Medline

Brooks R (1986) A robust layered control system for a mobile robot. IEEE Journal on Robotics and Automation 2:14-23. CrossRef

Bruce CJ, Goldberg ME, Bushnell MC, Stanton GB (1985) Primate frontal eye fields. II. Physiological and anatomical correlates of electrically evoked eye movements. J Neurophysiol 54:714-734. Medline

Burnham KP, Anderson DR (2002) Model selection and multi-model inference: a practical information-theoretic approach. New York: Springer.

Büschges A, Manira EA (1998) Sensory pathways and their modulation in the control of locomotion. Curr Opin Neurobiol 8:733-739. CrossRef Medline

Buschman TJ, Miller EK (2007) Top-down versus bottom-up control of attention in the prefrontal and posterior parietal cortices. Science 315: 1860-1862. CrossRef Medline

Carrasco M, Ling S, Read S (2004) Attention alters appearance. Nat Neurosci 7:308-313. CrossRef Medline

Cavanaugh J, Wurtz RH (2004) Subcortical modulation of attention counters change blindness. J Neurosci 24:11236-11243. CrossRef Medline

Clarke RJ, Zhang H, Gamlin PD (2003) Characteristics of the pupillary light reflex in the alert rhesus monkey. J Neurophysiol 89:3179-3189. CrossRef Medline

Delcomyn F (1999) Walking robots and the central and peripheral control of locomotion in insects. Autonomous Robots 7:259-270. CrossRef

Dineen JT, Hendrickson A (1983) Overlap of retinal and prestriate cortical pathways in the primate pretectum. Brain Res 278:250-254. CrossRef Medline

Ebitz RB, Platt ML (2015) Neuronal activity in primate dorsal anterior cingulate cortex signals task conflict and predicts adjustments in pupillinked arousal. Neuron 85:628-640. CrossRef Medline

Ebitz RB, Pearson JM, Platt ML (2014) Pupil size and social vigilance in rhesus macaques. Front Neurosci 8.

Ekstrom LB, Roelfsema PR, Arsenault JT, Bonmassar G, Vanduffel W (2008) Bottom-up dependent gating of frontal signals in early visual cortex. Science 321:414-417. CrossRef Medline

Elsley JK, Nagy B, Cushing SL, Corneil BD (2007) Widespread presaccadic recruitment of neck muscles by stimulation of the primate frontal eye fields. J Neurophysiol 98:1333-1354. CrossRef Medline

Frazor RA, Geisler WS (2006) Local luminance and contrast in natural images. Vision Res 46:1585-1598. CrossRef Medline

Friedman D, Hakerem G, Sutton S, Fleiss JL (1973) Effect of stimulus uncertainty on the pupillary dilation response and the vertex evoked potential. Electroencephalogr Clin Neurophysiol 34:475-484. CrossRef Medline

Gamlin PD, Zhang H, Clarke RJ (1995) Luminance neurons in the pretectal olivary nucleus mediate the pupillary light reflex in the rhesus monkey. Exp Brain Res 106:169-176. Medline

Gold JI, Shadlen MN (2000) Representation of a perceptual decision in developing oculomotor commands. Nature 404:390-394. CrossRef Medline

Gregoriou GG, Gotts SJ, Desimone R (2012) Cell-type-specific synchronization of neural activity in FEF with V4 during attention. Neuron 73:581594. CrossRef Medline

Graziano M, Taylor S, Moore T (2002) Complex movements evoked by microstimulation of precentral cortex. Neuron 34:841-851. CrossRef

Gregoriou GG, Rossi AF, Ungerleider LG, Desimone R (2014) Lesions of prefrontal cortex reduce attentional modulation of neuronal responses and synchrony in V4. Nat Neurosci 17:1003-1011. CrossRef Medline

Hakerem G, Sutton S (1966) Pupillary response at visual threshold. Nature 212:485-486. CrossRef Medline

Hanes DP, Wurtz RH (2001) Interaction of the frontal eye field and superior colliculus for saccade generation. J Neurophysiol 85:804815. Medline

Heitz RP, Schall JD (2012) Neural mechanisms of speed-accuracy tradeoff. Neuron 76:616-628. CrossRef Medline

Hodes R, Magoun H (1942) Pupillary and other responses from stimulation of the frontal cortex and basal telencephalon of the cat. J Comp Neurol 76:461-473. CrossRef

Huerta MF, Krubitzer LA, Kaas JH (1986) Frontal eye field as defined by intracortical microstimulation in squirrel monkeys, owl monkeys, and macaque monkeys: I. Subcortical connections. J Comp Neurol 253:415439. CrossRef Medline

Joshi S, Li Y, Kalwani RM, Gold JI (2016) Relationships between pupil di- 
ameter and neuronal activity in the locus coeruleus, colliculi, and cingulate cortex. Neuron 89:221-234. CrossRef Medline

Kimura T, Haggard P, Gomi H (2006) Transcranial magnetic stimulation over sensorimotor cortex disrupts anticipatory reflex gain modulation for skilled action. J Neurosci 26:9272-9281. CrossRef Medline

Krasne FB, Wine JJ (1975) Extrinsic modulation of crayfish escape behaviour. J Exp Biol 63:433-450. Medline

Künzle H, Akert K (1977) Efferent connections of cortical, area 8 (frontal eye field) in Macaca fascicularis: a reinvestigation using the autoradiographic technique. J Comp Neurol 173:147-164. CrossRef Medline

Laeng B, Endestad T (2012) Bright illusions reduce the eye's pupil. Proc Natl Acad Sci U S A 109:2162-2167. CrossRef Medline

Latto R, Cowey A (1971) Visual field defects after frontal eye-field lesions in monkeys. Brain Res 30:1-24. CrossRef Medline

Lehmann SJ, Corneil BD (2016) Transient pupil dilation after subsaccadic microstimulation of primate frontal eye fields. J Neurosci 36:3765-3776. CrossRef Medline

Leichnetz GR (1982) Connections between the frontal eye field and pretectum in the monkey: an anterograde/retrograde study using HRP gel and TMB neurohistochemistry. J Comp Neurol 207:394-404. CrossRef Medline

Leichnetz GR (1990) Preoccipital cortex receives a differential input from the frontal eye field and projects to the pretectal olivary nucleus and other visuomotor-related structures in the rhesus monkey. Vis Neurosci 5:123133. CrossRef Medline

Leichnetz GR (2001) Connections of the medial posterior parietal cortex (area 7m) in the monkey. Anat Rec 263:215-236. CrossRef Medline

Loewenfeld IE (1993) The pupil: anatomy, physiology, and clinical applications. Detroit: Wayne State University.

Lowenstein O, Loewenfeld IE (1950) Role of sympathetic and parasympathetic systems in reflex dilatation of the pupil: pupillographic studies. Arch Neurol Psychiatry 64:313-340. CrossRef Medline

Mathôt S, Van der Stigchel S (2015) New light on the mind's eye: the pupillary light response as active vision. Curr Dir Psychol Sci 24:374-378. CrossRef Medline

Mathôt S, van der Linden L, Grainger J, Vitu F (2013) The pupillary light response reveals the focus of covert visual attention. PLoS One 8:e78168. CrossRef Medline

Mathôt S, van der Linden L, Grainger J, Vitu F (2015) The pupillary light response reflects eye-movement preparation. J Exp Psychol Hum Percept Perform 41:28-35. CrossRef Medline

McAlonan K, Cavanaugh J, Wurtz RH (2008) Guarding the gateway to cortex with attention in visual thalamus. Nature 456:391-394. CrossRef Medline

McGinley MJ, Vinck M, Reimer J, Batista-Brito R, Zagha E, Cadwell CR, Tolias AS, Cardin JA, McCormick DA (2015) Waking state: rapid variations modulate neural and behavioral responses. Neuron 87:1143-1161. CrossRef Medline

Merrikhi Y, Clark K, Albarran E, Parsa M, Zirnsak M, Moore T, Noudoost B (2017) Spatial working memory alters the efficacy of input to visual cortex. Nat Commun. In press.

Miller EK, Cohen JD (2001) An integrative theory of prefrontal cortex function. Annu Rev Neurosci 24:167-202. CrossRef Medline

Monosov IE, Sheinberg DL, Thompson KG (2011) The effects of prefrontal cortex inactivation on object responses of single neurons in the inferotemporal cortex during visual search. J Neurosci 31:15956-15961. CrossRef Medline

Moore T, Armstrong KM (2003) Selective gating of visual signals by microstimulation of frontal cortex. Nature 421:370-373. CrossRef Medline

Moore T, Fallah M (2001) Control of eye movements and spatial attention. Proc Natl Acad Sci U S A 98:1273-1276. CrossRef Medline

Moore T, Fallah M (2004) Microstimulation of the frontal eye field and its effects on covert spatial attention. J Neurophysiol 91:152-162. Medline

Müller JR, Philiastides MG, Newsome WT (2005) Microstimulation of the superior colliculus focuses attention without moving the eyes. Proc Natl Acad Sci U S A 102:524-529. CrossRef Medline

Murphey DK, Maunsell JH (2008) Electrical microstimulation thresholds for behavioral detection and saccades in monkey frontal eye fields. Proc Natl Acad Sci U S A 105:7315-7320. CrossRef Medline

Nassar MR, Rumsey KM, Wilson RC, Parikh K, Heasly B, Gold JI (2012) Rational regulation of learning dynamics by pupil-linked arousal systems. Nat Neurosci 15:1040-1046. CrossRef Medline

Paxinos G, Huang XF, Toga AW (2000) The rhesus monkey brain in stereotaxic coordinates. Cambridge, MA: Academic Press.

Prescott TJ, Redgrave P, Gurney K (1999) Layered control architectures in robots and vertebrates. Adaptive Behavior 7:99-127. CrossRef

Robinson DA, Fuchs AF (1969) Eye movements evoked by stimulation of frontal eye fields. J Neurophysiol 32:637-648. Medline

Saleem KS, Logothetis NK (2012) A combined MRI and histology atlas of the rhesus monkey brain in stereotaxic coordinates. San Diego: Academic.

Salinas E, Thier P (2000) Gain modulation: a major computational principle of the central nervous system. Neuron 27:15-21. CrossRef Medline

Schafer RJ, Moore T (2007) Attention governs action in the primate frontal eye field. Neuron 56:541-551. CrossRef Medline

Schafer RJ, Moore T (2011) Selective attention from voluntary control of neurons in prefrontal cortex. Science 332:1568-1571. CrossRef Medline

Schall JD (1991) Neuronal activity related to visually guided saccades in the frontal eye fields of rhesus monkeys: comparison with supplementary eye fields. J Neurophysiol 66:559-579. Medline

Schlag J, Dassonville P, Schlag-Rey M (1998) Interaction of the two frontal eye fields before saccade onset. J Neurophysiol 79:64-72. Medline

Schlag-Rey M, Schlag J, Dassonville P (1992) How the frontal eye field can impose a saccade goal on superior colliculus neurons. J Neurophysiol 67:1003-1005. Medline

Segraves MA, Goldberg ME (1987) Functional properties of corticotectal neurons in the monkey's frontal eye field. J Neurophysiol 58:1387-1419. Medline

Sokolov EN (1963) Higher nervous functions: the orienting reflex. Annu Rev Physiol 25:545-580. CrossRef Medline

Squire RF, Noudoost B, Schafer RJ, Moore T (2013) Prefrontal contributions to visual selective attention. Annu Rev Neurosci 36:451-466. CrossRef Medline

Stanton GB, Goldberg ME, Bruce CJ (1988) Frontal eye field efferents in the macaque monkey: II. Topography of terminal fields in midbrain and pons. J Comp Neurol 271:493-506. CrossRef Medline

Stanton GB, Bruce CJ, Goldberg ME (1995) Topography of projections to posterior cortical areas from the macaque frontal eye fields. J Comp Neurol 353:291-305. CrossRef Medline

Steinhauer SR, Hakerem G (1992) The pupillary response in cognitive psychophysiology and schizophreniaa. Ann N Y Acad Sci 658:182-204. CrossRef Medline

Stelmack RM, Siddle DA (1982) Pupillary dilation as an index of the orienting reflex. Psychophysiology 19:706-708. CrossRef Medline

Tehovnik EJ, Sommer MA, Chou IH, Slocum WM, Schiller PH (2000) Eye fields in the frontal lobes of primates. Brain Res Rev 32:413-448. CrossRef Medline

Thompson KG, Biscoe KL, Sato TR (2005) Neuronal basis of covert spatial attention in the frontal eye field. J Neurosci 25:9479-9487. CrossRef Medline

Vu ET, Lee SC, Krasne FB (1993) The mechanism of tonic inhibition of crayfish escape behavior: distal inhibition and its functional significance. J Neurosci 13:4379-4393. Medline

Wang CA, Boehnke SE, White BJ, Munoz DP (2012) Microstimulation of the monkey superior colliculus induces pupil dilation without evoking saccades. J Neurosci 32:3629-3636. CrossRef Medline

Wang CA, Boehnke SE, Itti L, Munoz DP (2014) Transient pupil response is modulated by contrast-based saliency. J Neurosci 34:408-417. CrossRef Medline

Wang CA, Munoz DP (2015) A circuit for pupil orienting responses: implications for cognitive modulation of pupil size. Curr Opin Neurobiol 33: 134-140. CrossRef Medline

Ward AA Jr, Reed HL (1946) Mechanism of pupillary dilatation elicited by cortical stimulation. J Neurophysiol 9:329-335. Medline

Zirnsak M, Steinmetz NA, Noudoost B, Xu KZ, Moore T (2014) Visual space is compressed in prefrontal cortex before eye movements. Nature 507:504-507. CrossRef Medline 